\title{
International Federation of Eugenic Organisations
}

$\mathrm{T}^{\mathrm{T} x}$ HE eleventh Assembly of the International Federation of Eugenic Organisations was held in Zurich with various conferences on July 18-21 under the presidency of Prof. E. Rudin. Eighteen members of the Federation attended the Assembly, and visitors to the conferences brought the total number to more than fifty. As in previous years, the conferences were limited to a few topics, namely, feeblemindedness; the analysis and genetics of mental traits; twin studies and reports on eugenic progress in certain countries.

Mental deficiency or oligophrenia was restricted to two major questions, diagnosis and grading. Prof. Rudin, president, described the distinction made in Germany between oligophrenia as a psychiatric condition and what his school describes as normal stupidity. Prof. R. J. A. Berry gave an account of his long researches, and submitted the theory that mental defect can best be described as failure of development of the central nervous system; a condition which as such passes by indistinguishable grades from a pre-embryonic type in brain and cortex development to something which can best be characterised as less than the highest development known. $\mathrm{He}$ finds somatic and functional characters corresponding biologically to the various grades of lack of neural development. Dr. Rudolf, of Brentley Colony, Bristol, gave a lucid explanation of the way in which legislation has governed both the terminology and method of certification of mental deficiency in Great Britain.

A number of research workers in this field were present; amongst others, Dr. Wildenskow and Dr. Jens Smith, Denmark, Prof. Maier and Dr. Brugger, Switzerland, and Dr. Tietze and Dr. Hamburger, Austria. It would appear that legislation in both Germany and Great Britain has to some extent controlled the purely medico-biological treatment of the question. Denmark, with complete legislative control, has avoided this pitfall; the Danish psychiatrists, frankly admitting that an arbitrary line is drawn, below which lack of intelligence is regarded as warranting social control. Several speakers urged the evolutionary importance of this outlook; it might be hoped that, generation by generation, the point of poor development might be slightly raised if and as the average intelligence of the population rises progressively. Time did not allow of a full discussion on grading, but the only comparable base line still appears to be the BinetSimon tests. A comparative study is urgently required.

The second day began with a study of psychometry. Dr. Mjoen opening with a demonstration of his methods of testing musical ability. The demonstration of five of his twenty different tests created so much interest that discussion ran through the whole morning, concentrating mainly on the degree to which training would affect test of performance. Dr. Mjoen gave evidence from re-tests, proving that certain of the most diagnostic factors remained unchanged.

Prof. C. Spearman gave a lucid exposition of his analysis of intelligence into a general and special factors, and asked for help in the attempt which is being made both by national committees and by a committee of the International Federation of Eugenic Organisations to bring greater order and clarity into methods of psychological measurement.
Dr. Steggerda, who has just been appointed chairman of the International Federation of Eugenic Organisations Committee, gave an account of the difficulties of psychological studies of non-European races, from his own work amongst the Mayas in Yucatan, whites and negroes in Jamaica, Indians in Arizona and some other groups. Both he and Prof. Rodenwaldt stated that there can be no doubt of wide racial differences in mental faculty. For example, in music the tests satisfactory for Europeans would fail altogether to elicit the much finer discrimination common in the yellow races and negroes. It would appear that a careful and sympathetic study of the manner of life of any people should make it possible to eliminate those aspects of European tests, such as speed, which are wholly inapplicable in some other cultures. The afternoon was devoted to papers on twin studies introduced by Prof. Freiher von Verschuer of Berlin, the first problem to be tackled being methods of differentiation of identical and non. identical twins. From a study not yet published, he gave a chart showing the unreliability of judging from the chorion. In 52 cases with double chorea, 12 proved to be identical and 40 non-identical.

Reports on eugenic work occupied three sessions. Several of those charged with administration of the new German eugenic law had accepted the invitation of the Federation to give an account of the practical working of the new measures. Dr. Ruttke, directing popular education in protection of heredity, gave a clear outline of the whole policy, which may bo briefly summarised as: (a) Unification of State control throughout the nation. (b) Removal of unemployment (shown to have disintegrating effects on the sense of parental responsibility and family life). (c) De-urbanisation, which removes large families with self-supporting parents and good family history to peasant holdings which will be entailed. (d) Revision of marriage laws, making marriages for social or economic ends liable to be annulled. (e) Creation of bureaux for advice on heredity and marriage. $(f)$ Provision of loans for young persons of sound stock who desire to marry-a measure which goes hand in hand with the exclusion of women from those industries which can be served by unemployed men. $(g)$ The sterilisation law. Dr. Ruttke explained that the exclusion of criminals from the operation of this last measure is in order to remove any sense of degradation being connected with the operation; both in the courts and by popular propaganda, the ideal is put forward which has made sterilisation successful in California, that the citizen who accepts the operation with a sense of responsibility for posterity merits the esteem of the community. In regard to compulsion, he stated the fact not so widely known that patients may accept institutional treat. ment of segregation if they prefer it to sterilisation. (h) The Danish plan (also largely used in Switzerland) of castration for habitual sex offenders has been enacted as obligatory, the objective being double, both the curo of the condition in the individual and the protection of society. This last point is not necessarily regarded as a eugenic measure.

Reports of growing work and increasing interest were given from every country represented. These will be published in full in the report which will appear in the autumn, and will be obtainable from the Secretariat, price $2 s$. $6 d$. 